\title{
Iron deficiency and iron overload: effects of diet and genes
}

\author{
Wylie Burke ${ }^{1 *}$, Giuseppina Imperatore ${ }^{2}$ and Michelle Reyes ${ }^{2}$ \\ ${ }^{1}$ Department of Medical History and Ethics, University of Washington, Seattle, WA 98195, USA \\ ${ }^{2}$ Division of Nutrition and Physical Activity, National Center for Chronic Disease Prevention and Health Promotion, \\ Centers for Disease Control and Prevention, Atlanta, GA, USA
}

\begin{abstract}
Like most essential nutrients, Fe needs to be maintained in the body at a defined level for optimal health, with appropriate adaptation to varying Fe needs and supply. The primary mechanism for controlling Fe level is the regulation of Fe absorption. Several different proteins have been identified as contributors to the process. Despite a complex regulatory system, Fe disorders (both Fe deficiency and Fe overload) occur. Fe deficiency is a common problem worldwide, resulting from inadequate dietary $\mathrm{Fe}$ and blood loss. Complications include pre-term labour, developmental delay, and impaired work efficiency. No specific genetic syndromes causing isolated Fe deficiency have been described, but animal studies and clinical observations suggest that such a relationship may be a possibility. Conversely, the known causes of $\mathrm{Fe}$ overload are genetic. $\mathrm{Fe}$ overload is less common than Fe deficiency, but can result in serious medical complications, including cirrhosis, primary liver cancer, diabetes, cardiomyopathy and arthritis. The most common and best characterized syndrome of Fe overload is hereditary haemochromatosis (HHC), an autosomal recessive disorder. Mutations in the HFE protein cause HHC, but the clinical presentation is variable. Of particular interest is the factor that some HFE genotypes appear to be associated with protection from Fe deficiency. Other genetic variants in the regulatory pathway may influence the likelihood of Fe deficiency and Fe overload. Studies of genetic variants in HFE and other regulatory proteins provide important tools for studying the biological processes in $\mathrm{Fe}$ regulation. This work is likely to lead to new insights into Fe disorders and potentially to new therapeutic approaches. It will not be complete, however, until coordinated study of both genetic and nutritional factors is undertaken.
\end{abstract}

\section{Iron deficiency: Iron overload: Hereditary haemochromatosis: Iron regulatory pathway}

Fe is required for many life functions and is present in every cell. Its most important role is in $\mathrm{O}_{2}$ transport: $90 \%$ of the body's Fe is contained in erythrocytes as a component of the haemoglobin molecule. Fe also facilitates $\mathrm{O}_{2}$ use and storage in muscles, interacts with cytochromes in cellular metabolism, and serves as a cofactor for the function of several tissue enzymes (Yip et al. 1998). Like most essential nutrients, $\mathrm{Fe}$ needs to be maintained in the body at a defined level for optimal health. However, sources of dietary Fe are variable, and many disorders cause excessive loss of Fe. In addition, requirements for Fe differ at different stages of life. To maintain the optimal Fe level the body needs to adjust to varying $\mathrm{Fe}$ needs and supply.

The primary mechanism for controlling Fe level is the regulation of $\mathrm{Fe}$ absorption by the gastrointestinal tract (Yip et al. 1998; Andrews, 1999). Once Fe is absorbed the body has no known physiological mechanisms to control $\mathrm{Fe}$ excretion. The regulatory mechanism for Fe uptake is still under investigation, but several different proteins, and thus several genes, have been identified as contributors to the process (Feder et al. 1996; Andrews, 1999; Levy et al. 2000).

Despite a complex regulatory system, Fe disorders (both $\mathrm{Fe}$ deficiency and $\mathrm{Fe}$ overload) are important health problems. In the present review we consider current knowledge about the dietary and genetic contributors to $\mathrm{Fe}$ disorders, with special attention to the new insights that are emerging from the study of genetic disorders of Fe overload and their implications for public health. Our review addresses two questions: (1) to what extent do Fe disorders reflect problems in dietary Fe supply $v$. failures in the regulatory mechanism controlling Fe uptake; (2) how can knowledge about diet and genes help to reduce the problems of Fe deficiency and Fe overload?

\footnotetext{
Abbreviations: DMT1, divalent metal transporter; HHC, hereditary haemochromatosis; JH, juvenile haemochromatosis; RDA, recommended dietary allowance.

*Corresponding author: Dr Wylie Burke, fax +1 206685 7515, email wburke@u.washington.edu
} 


\section{Iron deficiency}

Fe deficiency is a common problem worldwide (Galan et al. 1998; Lawson et al. 1998; Yip et al. 1998), and includes a spectrum of conditions from mild $\mathrm{Fe}$ depletion without physiological impairment to Fe-deficiency anaemia. In the USA Fe deficiency is most common in young children, the elderly and women (Looker et al. 1997). Approximately $9 \%$ of children aged 1-2 years are $\mathrm{Fe}$ deficient, and 2-3\% remain $\mathrm{Fe}$ deficient in later childhood. Men have low rates of Fe deficiency until middle age $(<1 \%)$, but $4 \%$ of men aged 70-80 years are Fe deficient. Approximately $10 \%$ of women are Fe deficient during their reproductive years, and at all ages beyond infancy Fe deficiency is higher in women than in men (Looker et al. 1997).

$\mathrm{Fe}$ deficiency represents an imbalance between the body's need for $\mathrm{Fe}$ and the amount of $\mathrm{Fe}$ absorbed. In developed countries this imbalance is most commonly caused by an inadequate amount of $\mathrm{Fe}$ in the diet (Yip et al. 1998). In developing countries, by contrast, parasitic infections or blood loss are a common cause of $\mathrm{Fe}$ deficiency. Under normal conditions the absorption of $\mathrm{Fe}$ is sufficient to replace $\mathrm{Fe}$ losses, and to maintain both $\mathrm{Fe}$ stores and an adequate serum $\mathrm{Fe}$ level. A small amount of $\mathrm{Fe}$ is lost on a daily basis through faeces and desquamation of skin and mucosal cells (approximately $1 \mathrm{mg} / \mathrm{d}$ ). Gastrointestinal absorption normally varies with $\mathrm{Fe}$ status, but cannot always compensate for dietary insufficiency. During their reproductive years women lose additional Fe through menstruation (approximately $0 \cdot 3-0.5 \mathrm{mg} / \mathrm{d}$ ) and in childbirth (Yip et al. 1998; Andrews, 1999). Normally only about 5-15\% of the dietary $\mathrm{Fe}$ is absorbed; as a result, adult men require on average about $10 \mathrm{mg}$ dietary Fe/d and women of reproductive age about $15 \mathrm{mg} / \mathrm{d}$ (Yip et al. 1998). When the body's Fe needs increase for physiological or pathological reasons, $\mathrm{Fe}$ absorption increases (Andrews, 1999). Fe content of the diet and its bioavailability also play a critical role in the amount of $\mathrm{Fe}$ absorbed (Yip et al. 1998; Andrews, 1999).

The body conserves Fe once it has been absorbed. When erythrocytes are destroyed, the $\mathrm{Fe}$ in them is recycled. About $95 \%$ of the $\mathrm{Fe}$ used in production of new erythrocytes in men, for example, is estimated to come from recycled $\mathrm{Fe}$ (Yip et al. 1998). Fe is stored in soluble form as a component of serum ferritin and in insoluble form as a component of haemosiderin. A small amount of ferritin is present in the serum, but under normal circumstances most stores are found in the liver, bone marrow, spleen and skeletal muscles. The majority of $\mathrm{Fe}(60-70 \%)$ is stored as ferritin (Yip et al. 1998; Andrews, 1999). These stores are progressively depleted when inadequate amounts of $\mathrm{Fe}$ are absorbed.

In a 1994-6 survey by the US Department of Agriculture, more than half the children aged 1-2 years were found to have dietary Fe below the recommended dietary allowance (RDA; US Department of Agriculture, Agricultural Research Service, 1997). Similarly, a substantial proportion of women at all ages had Fe-poor diets. During their reproductive years only one-quarter of the women surveyed met the RDA for Fe (US Department of Agriculture, Agricultural Research Service, 1997). Data from other developed countries present a similar picture. In a British survey $12 \%$ of children aged 2 years had Fe-deficiency anaemia (Lawson et al. 1998). A French survey reported that $23 \%$ of menstruating women and $5 \%$ of postmenopausal women had $\mathrm{Fe}$ depletion (serum ferritin $<15 \mu \mathrm{g} / \mathrm{l}$; Galan et al. 1998). In addition, $93 \%$ of menstruating women had dietary $\mathrm{Fe}$ intakes lower than the RDA and $53 \%$ consumed less than two-thirds of the RDA (Galan et al. 1998). Rates of Fe deficiency are even higher in undeveloped countries and among vulnerable groups such as immigrants, racial and ethnic minorities and the economically disadvantaged (Lawson et al. 1998; Yip et al. 1998; Wharton, 1999).

Variation in Fe status may reflect the form as well as the amount of $\mathrm{Fe}$ in the diet. Bioavailability of $\mathrm{Fe}$ varies with several factors. Haem- $\mathrm{Fe}$ ( $\mathrm{Fe}$ bound to haemoglobin) has the greatest bioavailability (Yip et al. 1998), and is found in meat, poultry and fish. It constitutes $5-10 \%$ of the Fe in Western diets (Lawson et al. 1998; Yip et al. 1998) and is absorbed separately from other forms of $\mathrm{Fe}$, in an efficient uptake mechanism that may involve cellular endocytosis (Andrews, 1999). Absorption of non-haem-Fe is mediated by a cell-membrane protein (divalent metal transporter-1; DMT1) and is subject to a variety of modifying influences that may enhance or inhibit uptake, as shown in Table 1 (Yip et al. 1998; Andrews, 1999). The bioavailability of $\mathrm{Fe}$ may vary considerably in diets poor in haem-Fe, depending on both the food source containing the $\mathrm{Fe}$ and the other foods eaten with it. In addition $\mathrm{Fe}$ status influences the efficiency of $\mathrm{Fe}$ absorption (Yip et al. 1998; Andrews, 1999).

Fe deficiency is more likely to occur when Fe needs are increased. Thus, Fe deficiency is more common in women of child-bearing age, especially in pregnancy and in periods of rapid growth as in early childhood and adolescence, when Fe needs exceed what is usually supplied in the diet. Excess loss of $\mathrm{Fe}$, usually from blood loss, is also a factor (Yip et al. 1998; Andrews, 1999; Wharton, 1999). Fe loss is usually due to pathological conditions such as peptic ulcer disease, hookworm or other conditions causing bleeding. In infancy blood loss from the gastrointestinal tract can occur as a result of an allergic response to cow's milk (Wharton, 1999). Fe loss can also occur with menstrual bleeding, and with disorders that result in problems in gastrointestinal absorption (Provan, 1999).

About one-third to half the Americans with Fe deficiency have Fe-deficiency anaemia (Yip et al. 1998), with multiple clinical effects (Yip et al. 1998; Andrews, 1999). In infants Fe-deficiency anaemia can cause developmental delay and behavioural problems. In adults Fe-deficiency anaemia can impair work efficiency and cause symptoms of fatigue and

Table 1. Dietary factors that affect uptake of non-haem-iron (Yip et al. 1998; Skikne, 2000)

\begin{tabular}{ll}
\hline Enhancers of Fe absorption & Inhibitors of Fe absorption \\
\hline Vitamin C & Polyphenols (in some vegetables) \\
& Tannins (in tea) \\
Low pH & Phytates (in bran) \\
High protein intake & $\mathrm{Ca}$
\end{tabular}


malaise. Fe deficiency during pregnancy can result in preterm labour and low-birth-weight babies.

The prevalence of dietary intake below the RDA is substantially higher than the prevalence of Fe deficiency in both men and women (Yip et al. 1998). This observation suggests that many individuals can maintain adequate $\mathrm{Fe}$ levels in the face of suboptimal dietary Fe, and may be an indicator of varying efficiency of $\mathrm{Fe}$ uptake. If such variation occurs, both nutritional and genetic factors are likely contributors. No specific genetic syndromes causing isolated $\mathrm{Fe}$ deficiency have been described, but some anaemia syndromes suggest this possibility. For example, a congenital Fe-deficiency anaemia has been described that fails to respond to oral Fe supplements but is resolved with parenteral $\mathrm{Fe}$; an inherited disorder of gastrointestinal absorption of $\mathrm{Fe}$ could explain this clinical picture (Andrews, 1999). Mouse studies also provide support for this possibility. Differences in response to Fe-deficient diets have been observed in genetically-distinct mice (Morse et al. 1999), suggesting that genetic variation contributes to Fe status. In addition, mutations in two proteins involved in Fe metabolism have been shown to cause Fe deficiency in mice (Levy et al. 2000).

\section{Iron overload}

When excess $\mathrm{Fe}$ is absorbed for a prolonged period it exceeds the storage capacity provided by ferritin and haemosiderin. The result is the accumulation of catalytically-active $\mathrm{Fe}$ that causes tissue damage (Brown \& Bacon, 2000). Fe overload is less common than $\mathrm{Fe}$ deficiency, but can result in serious medical complications, including cirrhosis, primary liver cancer, diabetes, cardiomyopathy and arthritis (Bothwell et al. 1995). Most Fe overload occurs on a genetic basis. Data on the prevalence of Fe overload have derived primarily from studies in Europe, Australia and North America. In these studies biochemical evidence of $\mathrm{Fe}$ overload, i.e. serum $\mathrm{Fe}$ measures or tissue biopsies indicating excess Fe stores, occurs in up to $0.5 \%$ of the population (Bradley et al. 1998; Burt et al. 1998). The proportion of individuals with abnormal Fe measures who will ultimately develop clinical complications is unknown, however, and may be substantially lower (Cogswell et al. 1998). Fe overload is more common in men than in women. Symptoms typically occur at about 45 years or later. The prevalence of Fe overload among individuals of non-European ethnicity has not been systematically studied, but the condition has been described in sub-Saharan Africans and in African-Americans (Gorduek et al. 1992; Barton et al. 1995). One study of Hispanic Americans found a prevalence of $\mathrm{Fe}$ overload similar to that of European Americans (Centers for Disease Control and Prevention, 1996).

\section{Hereditary haemochromatosis}

Hereditary haemochromatosis (HHC) is the best characterized genetic disorder of Fe metabolism, and accounts for most of the Fe overload occurring in individuals of European descent. HHC is an autosomal recessive condition resulting in increased absorption of Fe from the gastro- intestinal tract, leading to a slow accumulation of excess $\mathrm{Fe}$ and the complications of Fe overload (Bothwell et al. 1995). Regulation of non-haem-Fe absorption still occurs in HHC (i.e. non-haem-Fe absorption increases or decreases based on Fe stores), but the regulatory system is impaired (Conrad et al. 2000). Further, absorption of haem-Fe appears to be insensitive to Fe stores; as a result, a net accumulation of Fe occurs with time (Conrad et al. 2000). Linkage of $\mathrm{HHC}$ to the human leucocyte antigen A3 complex on chromosome 6 was described more than 20 years ago (Simon et al. 1976), and the gene, now termed HFE (Bodmer et al. 1997), was identified in 1996 (Feder et al. 1996). With gene discovery, two missense mutations of the HFE gene, C282Y and H63D, were described, accounting for $88 \%$ of the 178 patients with $\mathrm{HHC}$ in the initial study. Studies of HHC and of these two HFE mutations provide several insights into Fe metabolism and the aetiology of Fe disorders.

First, the relationship between HFE genotype and the presence of clinical disease is complex. The majority of patients with HHC carry two copies of the C282Y mutation; this genotype carries the highest risk of Fe-overload disease (Burke et al. 2000). However, an increased risk of $\mathrm{Fe}$ overload is associated with other HFE genotypes as well, including genotypes that contain the less-severe H63D mutations. While most patients with HHC carry two HFE mutations, disease also occurs rarely in carriers, that is, individuals who carry only one HFE mutation (Burke et al. 2000). Fe-overload disease in individuals thought to be carriers could be due to additional mutations in the HFE gene. For example, a third HFE missense mutation, S65C, has been implicated in a mild form of HHC in one study (Mura et al. 1999). Seven other allelic variants of the HFE gene have now been reported (National Center for Biotechnology Information, 2000), but their clinical significance is still unknown. Conceivably these variants could contribute to disease in some carriers of $\mathrm{C} 282 \mathrm{Y}$ or H63D mutations, and could lead to variation in Fe uptake that is not sufficient to cause Fe overload.

More importantly, a high-risk genotype does not inevitably lead to Fe overload. Elderly individuals have been reported who have the $\mathrm{C} 282 \mathrm{Y} / \mathrm{C} 282 \mathrm{Y}$ genotype but are without Fe overload (Adams et al. 1997a; Bacon \& Sadiq, 1997; Olynyk et al. 1999). In addition, the severity of disease in symptomatic patients is variable (Adams, 1992; Niederau et al. 1996). These data indicate that the clinical effects of HFE deficiency may be either exacerbated or minimized by modifying factors.

One important modifier is gender. In family studies of haemochromatosis, equal numbers of brothers and sisters carry haemochromatosis genotypes, as would be expected for an autosomal recessive disorder. Among patients with clinical symptoms, however, the proportion of females is much lower, ranging from 11 to $35 \%$ in three large reported series of studies (Fargion et al. 1992; Niederau et al. 1996; Adams et al. 1997b). In a screening trial the prevalence of Fe overload ascertained by liver biopsy or phlebotomy was twice as frequent in males as females (Niederau et al. 1998). This gender difference has been attributed to Fe loss from menstruation, pregnancy and lactation, but could also be influenced by gender differences in $\mathrm{Fe}$ intake. 
Dietary factors are assumed to play a role in HHC disease expression, although this issue has not been studied systematically (Halliday, 1998). For example, Fe and vitamin C supplements and high intake of dietary $\mathrm{Fe}$, particularly in the form of haem-Fe, would be expected to increase the rate of $\mathrm{Fe}$ accumulation, and therefore the likelihood of symptomatic disease in HHC. Studies with rats have shown that hepatic Fe deposits similar to those seen in haemochromatosis can be produced with excess dietary Fe, although in this animal model the dietary Fe was forty to ninety times the control level, well beyond the variation expected in human dietary intake (Ramm, 2000). Excessive alcohol consumption has been shown to increase the likelihood of liver disease in individuals with HHC (Adams et al. 1997b); chronic hepatitis may have a similar effect (Fargion et al. 1992).

Finally, HFE mutations are common among individuals of European descent; about $10 \%$ carry the C282Y mutation and more than $20 \%$ carry the H63D mutation (Table 2). These high carrier rates suggest that carriers might have a selective advantage, possibly protection from Fe deficiency. Several studies demonstrate higher $\mathrm{Fe}$ levels in $\mathrm{HHC}$ carriers compared with non-carriers (Bulaj et al. 1996; Edwards et al. 2000; Whitfield et al. 2000). A populationbased twin study in Australia involving 3375 adult twins found that $\mathrm{Fe}$ status in both $\mathrm{C} 282 \mathrm{Y}$ and H63D heterozygotes differed from that of those with normal genotypes (Whitfield et al. 2000). The difference was small; less than $5 \%$ of phenotypic differences in Fe status were accounted for by these genes. Of equal importance, the twin study provided evidence for additional genetic factors that have a substantial effect on Fe status.

Two other studies failed to observe a difference in $\mathrm{Fe}$ status between C282Y carriers and those with a normal HFE genotype, and found no evidence for reduced rates of Fe-deficiency anaemia in carriers (Boulton et al. 2000; Rossi et al. 2000). However, these studies found reduced Fe deficiency among individuals with C282Y/H63D and H63D/H63D genotypes. These genotypes are associated with a low risk of $\mathrm{Fe}$ overload (Fe-overload disease is expected to develop in $1 \%$ or fewer of those with a C282Y/H62D genotype and in fewer than $1 \%$ of those with the H63D/H63D genotype; Burke et al. 2000), and both occur in approximately $2 \%$ of individuals of European descent (Table 2). Thus, at minimum, these studies indicate that at least $4 \%$ of northern Europeans carry genotypes offering protection from Fe deficiency. Differences between studies could be accounted for by differences in Fe intake or other modifying influences. Taken together, the studies are

Table 2. Prevalence of HFE genotypes in individuals of European descent (Hanson et al. 2000)

\begin{tabular}{lc}
\hline Genotype & $\begin{array}{c}\text { Prevalence (\%: average from published } \\
\text { studies) }\end{array}$ \\
\hline C282Y/C282Y & 0.4 \\
C282Y/H63D & 1.8 \\
H63D/H63D & 2.0 \\
C282Y/+ & 9.2 \\
H63D/+ & 21.6 \\
\hline
\end{tabular}

consistent with improved Fe status in at least some HHC carriers.

\section{Other iron-overload syndromes}

Genetically-distinct syndromes of Fe overload other than HHC have been described. The additional syndromes further illustrate the complexity of the Fe regulatory system. Two of these conditions (non-human leucocyte antigenlinked haemochromatosis and juvenile haemochromatosis (JH)) are autosomal recessive, and thus could represent other genetic conditions associated with a selective advantage for carriers.

Hereditary haemochromatosis-like syndrome, unlinked to the chromosome 6 human leucocyte antigen region. Families have been described with an inherited Fe-overload syndrome that is clinically indistinguishable from $\mathrm{HHC}$ but is unlinked to chromosome 6 (Pietrangelo et al. 1999). A recent Italian study reported the identification of a new gene that is linked to Fe-overload disease in two Sicilian families with this disorder (Camaschella et al. 2000). The gene, TFR2, codes for a protein which has a $66 \%$ homology to the transferrin receptor, binds transferrin and is presumed to play a role in cellular Fe uptake.

Juvenile haemochromatosis. Juvenile haemochromatosis (JH) differs from typical HCC by its severity. While clinical expression of HHC is more common in males, $\mathrm{JH}$ affects both sexes equally. Fe accumulation begins early in life and causes clinical symptoms before the age of 30 years (Kaltwasser, 2000). If untreated, the disease is lethal due to cardiac complications. Although the organ damage in $\mathrm{JH}$ is more severe, Fe distribution is similar to that in $\mathrm{HHC}$, as inferred by liver biopsies and autopsy findings (Kaltwasser, 2000). In patients with JH the rate of Fe absorption is two- to fivefold higher than that in patients with HHC. The gene for $\mathrm{JH}$ has recently been mapped to chromosome 1 (Roetto et al. 1999); the function of the protein for which it codes is unknown.

Iron overload in Africans and African-Americans. Fe overload has been observed among Bantus in sub-Saharan Africa and among African-Americans. Fe overload in African-Americans differs clinically from $\mathrm{HHC}$ in that transferrin saturation levels are often lower and HFE mutations have not been found in affected individuals (Barton et al. 1995). In addition, the pattern of Fe deposition in the liver differs. In Fe overload in Africans Fe accumulates primarily in reticulo-endothelial cells. In Africa $\mathrm{Fe}$ overload was originally observed in association with alcoholic beverages made in iron pots, and was assumed to be caused by high Fe intake. However, Fe overload was also found among individuals who were not heavy drinkers, and not all drinkers developed Fe overload. Family studies suggest genetics as a causative factor, but the genetics of these Fe-overload conditions remain poorly understood (Gorduek et al. 1992; Bloom et al. 2000).

Other iron-overload syndromes. Rare families have been reported with atransferrinaemia and Fe overload; the cause of the disorder has not been defined (Beutler, 2000). In addition, Fe overload in neural tissue, and to a lesser extent in the liver, has been observed in rare patients with caeruloplasmin deficiency secondary to mutations in the 
caeruloplasmin gene; these patients also demonstrate Fe-deficiency anaemia (Andrews, 1999; Beutler, 2000).

\section{The regulatory mechanism}

Growing knowledge about HHC and other genetic conditions leading to $\mathrm{Fe}$ overload provides important tools for the study of the Fe regulatory system. Mapping of the HFE gene led to identification of a previously-unrecognized function, and provided a basis for cellular studies to clarify the biological processes involving the HFE protein. The HFE example also illustrates the contribution of animal models to the understanding of the genetic components of a complex biological system. Mouse models lacking specific protein functions, including a 'knockout' mouse that lacks the HFE protein function, have been employed to investigate the effect of the loss of specific proteins in the regulatory pathway and interactions between different proteins (Levy et al. 2000). In vitro studies and clinical observations of Fe-overloaded patients, particularly those with HHC, also contribute to a greater understanding of the regulatory process, which is reviewed in detail elsewhere (Elsenstein \& Blemings, 1998; Andrews, 1999; Conrad et al. 2000; Skikne, 2000).

The most well-defined proteins involved in the $\mathrm{Fe}$ regulatory process are summarized in Table 3 . From studies of these proteins in human and animal models, several interactions related to Fe overload and Fe deficiency can now be described. DMT1, the membrane transporter, mediates absorption of non-haem-Fe. It is assumed to interact with intestinal brush-border enzymes that reduce $\mathrm{Fe}$ to its $\mathrm{Fe}^{3+}$ form to facilitate Fe uptake (Andrews, 1999). Loss of DMT1 causes $\mathrm{Fe}$ deficiency in mice and prevents Fe loading in
HFE-deficient mice (Levy et al. 2000). However, when the HFE protein is absent DMT1-deficient mice absorb marginally more $\mathrm{Fe}$ than when it is present (Levy et al. 2000), suggesting a small amount of absorption by an alternate uptake pathway that might be regulated by HFE.

HFE binds to $\beta_{2}$-microglobulin, a protein that also binds to other major histocompatibility class I proteins (Feder et al. 1997). In mouse models loss of $\beta_{2}$-microglobulin results in both Fe loading and immunological abnormalities (Levy et al. 2000). In addition, mice lacking either HFE or $\beta_{2}$-microglobulin develop Fe overload (Zhou et al. 1998; Levy et al. 2000), and a more severe Fe overload is observed if both proteins are lacking (Levy et al. 2000). The HFE protein product also binds to the transferrin receptor and reduces its affinity for Fe-loaded transferrin by five- to tenfold (Feder et al. 1998). The C282Y mutation alters the HFE protein structure, disrupting $\beta_{2}$-microglobulin association and its transport to and presentation on the cell surface (Lebron et al. 1998). The H63D mutation does not prevent the $\beta_{2}$-microglobulin association or cell surface expression, consistent with its milder clinical effect (Waheed et al. 1997). The localization of the HFE protein in the crypt cells of the duodenal site of dietary $\mathrm{Fe}$ absorption, and its association with transferrin receptor in these cells are consistent with its presumed role in the regulation of $\mathrm{Fe}$ absorption (Parkilla et al. 1997; Waheed et al. 1999).

The delineation of the role of these and other proteins in the regulatory pathway achieved thus far by genetic analysis still leaves many questions unanswered. Clinical and animal studies indicate that the rate of $\mathrm{Fe}$ absorption is influenced by three factors: the amount of $\mathrm{Fe}$ absorbed from the diet; the amount of Fe stored in the body; the rate of erythrocyte production (Andrews, 1999). The feedback mechanisms that

Table 3. Well-defined proteins in iron regulation

\begin{tabular}{ll}
\hline Protein & Function \\
\hline $\begin{array}{c}\text { Divalent metal } \\
\text { transporter-1 (DMT1) }\end{array}$ & $\begin{array}{c}\text { Major transmembrane importer molecule } \\
\text { for non-haem-Fe; also involved in } \\
\text { transport of other metals }\end{array}$
\end{tabular}

HFE

Ferritin

Transferrin

Transferrin receptor

Caeruloplasmin and homologue hephaestin
Effect of loss of function (mouse and human studies)

Human: no mutations known

Mouse: mice homozygous for the mk mutation have marked reduction in DMT1 function and intestinal absorption of $\mathrm{Fe}$ and have microcytic anaemia (Edwards \& Hoke, 1972; Levy et al. 2000)

HFE has a role in Fe absorption that is not Human: mutations in HFE account for the majority of patients with yet well defined. It binds to $\beta_{2}$-microglobulin; this complex interacts with the transferrin receptor, reducing affinity of the receptor for Fe-loaded transferrin

Ferritin subunits form an intracellular storage structure for $\mathrm{Fe}$

Transport molecule for Fe hereditary haemochromatosis (HHC; Feder et al. 1996)

Mouse: A 'knockout' mouse lacking HFE function develops Fe overload similar to that seen in HHC (Zhou et al. 1998)

Human: no mutations known

Mouse: no mutations known

Human: rare families have been described with atransferrinaemia and Fe overload (Beutler, 2000)

Mouse: no mutations known

Human: no mutations known

Mouse: mice lacking transferrin receptor die during embryogenesis of severe Fe deficiency (Levy et al. 2000) cellular uptake. As already noted transferrin receptor complexes with HFE- $\beta_{2}$-microglobulin

Appears to mediate movement of $\mathrm{Fe}$ out of body tissues
Human: acaeruloplasminaemia due to a caeruloplasmin gene mutation results in Fe-deficiency anaemia and neural damage related to excess Fe (Andrews, 1999)

Mouse: mice deficient in hephaestin have inefficient transfer of $\mathrm{Fe}$ into the circulation (Levy et al. 2000) 
control absorption are only poorly understood. At least two Fe regulatory proteins have been identified. Their function occurs at least in part through regulation of the rate of transcription of key proteins in the absorption pathway, e.g. proteins like DMT1, transferrin, ferritin and HFE (Elsenstein \& Blemings, 1998). This regulatory function is mediated by $\mathrm{Fe}$ responsive elements, structural elements within mRNA molecules that control the rate of mRNA transcription (Elsenstein \& Blemings, 1998). The same feedback mechanisms are also presumed to influence cellular uptake of Fe.

\section{Implications for public health}

In developed countries Fe deficiency appears to be largely the result of inadequate nutrition whereas $\mathrm{Fe}$ overload is largely the result of genetic disorders. However, clinical observations and the complexity of the Fe regulatory system suggest that neither disorder has a simple causative mechanism. Genetic variation in the multiple proteins that contribute to $\mathrm{Fe}$ regulation could influence $\mathrm{Fe}$ status in a variety of ways that either increase or decrease the likelihood of different $\mathrm{Fe}$ disorders.

Common variants in the genes coding for DMT1 or other regulatory proteins might, for example, interact with the HFE protein in ways that influence the clinical expression of HHC. Study of other genetic disorders of Fe overload, such as JH-type African Fe overload and non-human leucocyte antigen-linked haemochromatosis, will help to clarify this possibility through the identification and characterization of other proteins in the $\mathrm{Fe}$ regulatory system. Non-genetic factors also appear to play a role in Fe overload, as indicated by the variation in clinical outcome among individuals with the C282Y/C282Y HFE genotype, including the marked difference between men and women in the prevalence of clinical symptoms of HHC. The role of diet and nutrition in $\mathrm{Fe}$ overload disease, especially in gene expression, remains to be determined.

Genetic variants in the Fe regulatory systems are also likely to influence the likelihood of Fe deficiency, as is seen in mouse models (Levy et al. 2000). Some variants may predispose to $\mathrm{Fe}$ deficiency, while others may provide protection; the $\mathrm{C} 282 \mathrm{Y}$ and H63D mutation in the HFE gene appear to be examples of the latter. From an evolutionary perspective the existence of common mutations that enhance $\mathrm{Fe}$ status is of great interest, given the high prevalence of Fe deficiency. If carriers of C282Y and H63D mutations have an advantage in Fe retention, HHC (and by extension, other autosomal recessive syndromes leading to $\mathrm{Fe}$ overload) might be the result of a selection process favouring carrier genotypes. The adverse consequences of such genotypes may be apparent only in developed societies that offer access to protein-rich diets and longer lifespans; in previous eras even those with highest-risk genotypes might have had a survival advantage. The physiological advantage of mutation carriers is likely to remain important until medical science offers better solutions to the problem of $\mathrm{Fe}$ deficiency.

The analytical work made possible by genetics will not be complete until the interaction between dietary and genetic factors is fully understood. The genetic factors that influence $\mathrm{Fe}$ absorption are likely to respond variably to dietary factors. Thus, polymorphisms in proteins involved in non-haem-Fe absorption, e.g. ferroreductases and DMT1, could influence the efficacy of Fe supplements. Variation in proteins involved in the separate uptake pathway for haem-Fe could have important implications for the importance of haem $v$. non-haem sources of $\mathrm{Fe}$ in the diet, and might modify outcome in HHC. Dietary Fe may have other effects on the feedback mechanisms within the regulatory pathway.

As data accumulate in the future, it may become possible to adjust diet to genotype, to minimize risks of both $\mathrm{Fe}$ deficiency and $\mathrm{Fe}$ overload. In addition, delineation of the regulatory pathway may lead to drug treatments that block known protein functions, either to enhance or reduce $\mathrm{Fe}$ uptake. Solving the dual problems of Fe deficiency and $\mathrm{Fe}$ overload will require coordinated study of genes and diet, and may ultimately lead to innovative strategies to prevent Fe disorders.

\section{References}

Adams PC (1992) Intrafamilial variation in hereditary hemochromatosis. Digestive Diseases and Sciences 37, 361-363.

Adams PC, Campion ML, Gandon G, LeGall JY, David V \& Jouanolle AM (1997a) Clinical and family studies in genetics hemochromatosis: Microsatellite and HFE studies in five atypical families. Hepatology 26, 991-995.

Adams PC, Deugnier Y, Moirand R \& Brissot P (1997b) The relationship between iron overload, clinical symptoms and age in 410 hemochromatosis patients. Hepatology 25, 162-166.

Andrews NC (1999) Disorders of iron metabolism. New England Journal of Medicine 341, 1986-1995.

Bacon BR \& Sadiq SA (1997) Hereditary hemochromatosis: presentation and diagnosis in the 1990s. American Journal of Gastroenterology 92, 784-789.

Barton JC, Edwards CQ, Bertoli LF, Shroyer TW \& Hudson SL (1995) Iron overload in African Americans. American Journal of Medicine 99, 616-623.

Beutler E (2000) Evidence for multiple hemochromatosis genes. In Hemochromatosis, pp. 99-103 [JC Barton and CQ Edwards, editors]. New York: Cambridge University Press.

Bloom PD, Burstien GR \& Gorduek VR (2000) Iron overload in African Americans. In Hemochromatosis, pp. 475-484 [JC Barton and CQ Edwards, editors]. New York: Cambridge University Press.

Bodmer JG, Marsh SG, Albert ED, Bodmer WF, Bontrop RE, Charron D, Dupont B, Erlich HA, Fauchet R, Mach B, Mayr WR, Parham P, Sasazuki T, Schreuder GM, Strominger JL, Svejgaard A \& Terasaki PI (1997) Nomenclature for factors of the HLA system, 1996. Vox Sanguinis 73, 105-130.

Bothwell TH, Charlton RW \& Motulsky AG (1995) Hemochromatosis. In The Metabolic and Molecular Bases of Inherited Disease, 7th ed., pp.2237-2270 [CR Scriver, AL Beaudet, WS Sly and D Valle, editors]. New York: McGraw Hill.

Boulton F, Collis D, Inskip H, Paes H \& Garlick M (2000) A study of iron and HFE status in blood donors, including a group who failed the initial screen for anaemia. British Journal of Haematology 108, 434-439.

Bradley L, Johnson D, Palomaki G, Haddow J, Robertson N \& Ferrie R (1998) Hereditary haemochromatosis mutation frequencies in the general population. Journal of Medical Screening 5, 34-36. 
Brown KE \& Bacon BR (2000) Hepatic iron metabolism in hemochromatosis. In Hemochromatosis, pp. 157-162 [JC Barton and CQ Edwards, editors]. New York: Cambridge University Press.

Bulaj ZJ, Griffen LM, Jorde LB, Edwards CQ \& Kushner JP (1996) Clinical and biochemical abnormalities in people heterozygous for hemochromatosis. New England Journal of Medicine 335, 1799-1805.

Burke W, Imparatore G, McDonnell SM, Baron RC \& Khoury MJ (2000) Contribution of different HFE genotypes to iron overload: a pooled analysis. Genetics in Medicine 2, 271-277.

Burt MJ, George PM, Upton JD, Collett JA, Frampton CM, Chapman TM, Walmsley TA \& Chapman BA (1998) The significance of haemochromatosis gene mutations in the general population: implications for screening. Gut $\mathbf{4 3}, 830-836$.

Camaschella C, Roetto A, Cali A, De Gobbi M, Garozzo G, Carella M, Majarano N, Totaro A \& Gasparini P (2000) The gene TFR2 is mutated in a new type of haemochromatosis mapping to $7 \mathrm{q} 22$. Nature Genetics 25, 14-15.

Centers for Disease Control and Prevention (1996) Iron overload disorders among Hispanics-San Diego, California, 1995. Morbidity and Mortality Weekly Report 45, 991-993.

Cogswell ME, McDonnell SM, Khoury MJ, Franks AL, Burke W \& Brittenham G (1998) Iron overload, public health and genetics: evaluating the evidence for hemochromatosis screening. Annals of Internal Medicine 129, 971-979.

Conrad, ME, Umbreit JN, Moore EG \& Parmley RT (2000) Intestinal iron absorption in hemochromatosis. In Hemochromatosis, pp. 118-130 [JC Barton and CQ Edwards, editors]. New York: Cambridge University Press.

Edwards CQ, Griffen LM, Bulaj ZJ, Ajioka RS \& Kushner JP (2000) The iron phenotype of hemochromatosis heterozygotes. In Hemochromatosis, pp. 411-418 [JC Barton and CQ Edwards, editors]. New York: Cambridge University Press.

Edwards JA \& Hoke JE (1972) Defect of intestinal mucosal iron uptake in mice with hereditary microcytic anemia. Proceedings of the Society for Experimental Biology and Medicine 141, 81-84.

Elsenstein RS \& Blemings KP (1998) Iron regulatory proteins, iron responsive elements and iron hemostasis. Journal of Nutrition 128, 2295-2298.

Fargion S, Mandelli C, Piperno A, Cesana B, Fracanzani AL, Fraquelli M, Bianchi PA, Fiorelli G \& Conte D (1992) Survival and prognostic factors in 212 Italian patients with genetic hemochromatosis. Hepatology 15, 655-659.

Feder JN, Gnirke A, Thomas W, Tsuchihashi Z, Ruddy DA, Basava A et al. (1996) A novel MHC class I-like gene is mutated in patients with hereditary hemochromatosis. Nature Genetics $\mathbf{1 3}$, 399-408.

Feder JN, Penny DM, Irrinki A, Lee VK, Lebron JA, Watson N, Tsuchihashi Z, Sigal E, Bjorkman PJ \& Schatzman RC (1998) The hemochromatosis gene product complexes with the transferrin receptor and lowers its affinity for ligand binding. Proceedings of the National Academy of Sciences USA 95, 1472-1477.

Feder JN, Tsuchihashi Z, Irrinki A, Lee VK, Mapa FA, Morikang E, Prass CE, Starnes SM, Wolff RK, Parkkila S, Sly WS \& Schatzman RC (1997) The hemochromatosis founder mutation in HLA-H disrupts beta-2-microglobulin interactions and cell surface expression. Journal of Biological Chemistry 272, 14025-14028.

Galan P, Yoon HC, Preziosi P, Viteri F, Valeix P, Briancon S, Malvy D, Roussel AM, Favier A \& Hercberg S (1998) Determining factors in the iron status of adult women in the SU.VI. MAX study. European Journal of Clinical Nutrition 52, 383-388.
Gordeuk V, Mukiibi J, Hasstedt SJ, Samowitz W, Edwards CQ, West G et al. (1992) Iron overload in Africa: interaction between a gene and dietary iron content. New England Journal of Medicine 326, 95-100.

Halliday JW (1998) Hemochromatosis and iron needs. Nutrition Reviews 56, Suppl. II, S30-S37.

Hanson E, Imperatore G \& Burke W (2000) HFE gene and hereditary hemochromatosis. American Journal of Epidemiology (In the Press).

Kaltwasser JP (2000) Juvenile hemochromatosis. In Hemochromatosis, pp. 318-325 [JC Barton and CQ Edwards, editors]. New York: Cambridge University Press.

Lawson MS, Thomas M \& Hardiman A (1998) Iron status of Asian children aged 2 years living in England. Archives of Disease in Childhood 78, 420-426.

Looker AC, Dallman PR, Carroll MD, Gunter EW \& Johnson CL (1997) Prevalence of iron deficiency in the United States. Journal of the American Medical Association 277, 973-976.

Lebron JA, Bennet MJ, Vaughn DE, Chirino AJ, Snow PM, Mintier GA, Feder JN \& Bjorkman PJ (1998) Crystal structure of the hemochromatosis protein $\mathrm{HFE}$ and characterization of its interaction with transferrin receptor. Cell 93, 111-123.

Levy JE, Montross LK \& Andrews NC (2000) Genes that modify the hemochromatosis phenotype in mice. Journal of Clinical Investigation 105, 1209-1216.

Morse AC, Beard JL \& Jones BC (1999) A genetic developmental model of iron deficiency: biological aspects. Proceedings of the Society for Experimental Biology and Medicine 220, 147-152.

Mura C, Raguenes O \& Ferec C (1999) HFE mutation analysis in 711 hemochromatosis probands: evidence for $\mathrm{S} 65 \mathrm{C}$ implication in mild form of hemochromatosis. Blood 93, 2502-2506.

National Center for Biotechnology Information (2000) Hemochromatosis; HFE. http://www.ncbi.nlm.nih.gov/htbin-post/Omin

Niederau C, Fischer R, Purschel A, Stremmel W, Haussinger D \& Strohmeyer G (1996) Long-term survival in patients with hereditary hemochromatosis. Gastroenterology $\mathbf{1 1 0}$, 1107-1119.

Niederau C, Niederau CM, Lange S, Littauer A, Abdel-Jalil N, Maurer M, Haussinger D \& Strohmeyer G (1998) Screening for hemochromatosis and iron deficiency in employees and primary care patients in Western Germany. Annals of Internal Medicine 128, 337-345.

Olynyk JK, Cullen DJ, Aquila S, Rossi E, Summerville L \& Powell LW (1999) A population-based study of the clinical expression of the hemochromatosis gene. New England Journal of Medicine 341, 718-724.

Parkilla S, Waheed A, Britton RS, Feder JN, Tsuchihashi Z, Schatzman RC, Bacon BR \& Sly WS (1997) Immunohistochemistry of HLA-H, the protein defective in patients with hemochromatosis, reveals unique pattern of expression in hereditary hemochromatosis. Proceedings of the National Academy of Sciences USA 94, 2534-2539.

Pietrangelo A, Montosi G, Totaro A, Garuti C, Conte D, Cassanelli S, Fraquelli M, Sardini C, Vasta F \& Gasparini P (1998) Hereditary hemochromatosis in adults without pathogenic mutations in the hemochromatosis gene. New England Journal of Medicine 341, 725-732.

Provan D (1999) Mechanisms and management of iron deficiency. British Journal of Haematology 105, Suppl. 1, 19-26.

Ramm GA (2000) Animal models of iron overload based on excess exogenous iron. In Hemochromatosis, pp. 494-507 [JC Barton and CQ Edwards, editors]. New York: Cambridge University Press.

Roetto A, Totaro A, Cazzola M, Ciciliano M, Bosio S, D'Ascola G, Carella M, Zelante L, Kelly AL, Cox TM, Gasparini P \& 
Camaschella C (1999) Juvenile hemochromatosis locus maps to chormosome 1q. American Journal of Human Genetics 64 , $1388-1393$.

Rossi E, Olynyk JK, Cullen DJ, Papadopoulos G, Bulsara M, Summerville L \& Powell LW (2000) Compound heterozygous hemochromatosis genotype predicts increased iron and erythrocyte indices in women. Clinical Chemistry 46, 162-166.

Simon M, Bourel M, Fauchet R \& Genetet B (1976) Association of HLA-A3 and HLA-B14 with idiopathic haemochromatosis. Gut 5, 332-334.

Skikne BS (2000) Intestinal iron-binding proteins. In Hemochromatosis, pp. 107-117 [JC Barton and CQ Edwards, editors]. New York: Cambridge University Press.

US Department of Agriculture, Agricultural Research Service (1997) Results from USDA's 1994-96 Continuing Survey of Food Intakes by Individuals and 1994-96 Diet and Health Knowledge Survey. http://www.barc.usda.gov/bhnrc/ foodsurvey/

Waheed A, Parkkila S, Saarnio J, Fleming RE, Zhou XY, Tomatsu S, Britton RS, Bacon BR \& Sly WS (1999) Association of HFE protein with transferrin receptor in crypt enterocytes of human duodenum. Proceedings of the National Academy of Sciences USA 96, 1579-1584.
Waheed A, Parkkila S, Zhou XY, Tomatsu S, Tsuchihashi Z, Feder JN, Scatzman RC, Britton RS, Bacon BR \& Sly WS (1997) Hereditary hemochromatosis: effects of C282Y and H63D mutations on association with beta-2-microglobulin, intracellular processing, and cell surface expression of the HFE protein in COS-7 cells. Proceedings of the National Academy of Sciences USA 94, 12384-12389.

Wharton BA (1999) Iron deficiency in children: detection and prevention. British Journal of Haematology 106, 270-280.

Whitfield JB, Cullen LM, Jazwinska EC, Powell LW, Heath AC, Zhu G, Duffy DL \& Martin NG (2000) Effects of HFE C282Y and $\mathrm{H} 63 \mathrm{D}$ polymorphisms and polygenic background on iron stores in a large community sample of twins. American Journal of Human Genetics 66, 1246-1258.

Yip R, Parvanta I, Cogswell ME, McDonnell SM, Bowman BA, Gurmmer-Strawn LM \& Trowbridge F (1998) Recommendations to prevent and control iron deficiency in the United States. Morbidity and Mortality Weekly Report 47, 1-29.

Zhou XY, Tomatsu S, Fleming RE, Parkkila S, Waheed A, Jiang J, Fei Y, Brunt EM, Ruddy DA, Prass CE, Schatzman RC, O’Neill R, Britton RS, Bacon BR \& Sly WS (1998) HFE gene knockout produces mouse model of hereditary hemochromatosis. Proceedings of the National Academy of Sciences USA 95, 2492-2497. 